\title{
A PROPOSTA CURRICULAR DE QUÍMICA DO ESTADO DE MINAS GERAIS: FUNDAMENTOS E PRESSUPOSTOS
}

Eduardo Fleury Mortimer

Faculdade de Educação - UFMG - Belo Horizonte - MG

Andréa Horta Machado e Lilavate Izapovitz Romanelli

Colégio Técnico da UFMG - Av. Antônio Carlos 6627 - 31270-901 - Belo Horizonte - MG

Recebido em 26/4/99; aceito em 31/5/99

\begin{abstract}
THE HIGH SCHOOL CHEMISTRY CURRICULUM OF THE STATE OF MINAS GERAIS: PHILOSOFICAL FOUNDATIONS. This article presents the basic ideas that oriented the elaboration of the new Chemistry Curriculum for the High Schools in the State of Minas Gerais, Brazil. The main features of traditional Brazilian Chemistry Curriculum are critically discussed, namely, the excessive number of concepts, the overemphasis in procedures and rituals instead of chemical principles and the lack of relationship between the concepts and the social, technological and environmental contexts. Trying to overcome these features, the proposed curriculum deals with a fewer number of concepts, clearly related in a conceptual structure, opening space to a balanced emphasis on phenomena, theory and representation, and on conceptual and contextual aspects of chemical knowledge.
\end{abstract}

Keywords: Chemistry curriculum; high school chemistry; conceptual structure; contextual curriculum.

\section{INTRODUÇÃO}

Neste artigo apresentamos as idéias básicas que nortearam a elaboração do novo currículo de Química para o Ensino Médio no Estado de Minas Gerais ${ }^{1}$, que fez parte do Programa Piloto de Inovação Curricular e de Capacitação Docente para o Ensino Médio da Secretaria de Estado da Educação de Minas Gerais, realizado nos anos de 1997 e 1998. Apresentamos também a lista de temas que foi sugerida para os módulos que compõem o currículo e algumas alternativas de como elaborar uma proposta curricular mais centrada nos contextos de vivência social, ambiental e tecnológica do aluno ou uma outra mais centrada nos conceitos químicos.

Antes de iniciar a apresentação das idéias que foram utilizadas na elaboração da proposta curricular, é conveniente relatar um pouco da filosofia do programa piloto e do processo de reformulação curricular, que previa ao mesmo tempo a participação dos professores na elaboração da proposta e na produção de módulos didáticos para que a proposta pudesse "sair do papel" e ser implementada nas escolas.

Umas das idéias básicas do Programa é a concepção de um currículo modular que propicia ao professor flexibilidade de compor o currículo de acordo com seus interesses e aptidões, sua realidade regional e as características de seus alunos. Para que o professor se torne sujeito dessa proposta e possa se interessar em implementá-la em suas salas de aula, é necessário que ele participe ativamente do processo e seja capaz, ele mesmo, de elaborar módulos didáticos contemplando temas da proposta. Neste sentido, o processo de capacitação dos professores, parte fundamental da reformulação curricular, não teve por objetivo "treiná-los" no uso de materiais didáticos elaborados por especialistas, mas torná-los capazes de elaborar sua própria proposta curricular e os materiais didáticos necessários para sua implementação.

Nessa proposta, nosso papel, como especialistas, passa a ser o de trazer à tona os pressupostos teóricos que orientam as

e-mail: mortimer@dedalus.lcc.ufmg.br

e-mail: andreah@coltec.ufmg.br propostas curriculares existentes, formular novos pressupostos que possam ser compartilhados com os professores e formular módulos exemplares para que os professores possam ter uma visão de como produzir materiais didáticos modulares e ao mesmo tempo possam avaliar as dificuldades relacionadas à implementação da proposta curricular quando da implementação desses módulos em suas salas de aula.

O Programa de capacitação envolveu a proposta de atividades que foram desenvolvidas em 3 encontros com os professores, de 40 horas cada um, ao longo de 1 ano e $1 / 2$.

Esses encontros foram concebidos de modo que o primeiro deles discutisse os temas do currículo do primeiro ano do Ensino Médio. Os temas de segundo e terceiro anos seriam discutidos no segundo e terceiro encontros, respectivamente. As 40 horas previstas aconteciam ao longo de uma semana nas instalações da Fundação Helena Antipoff, localizada em Ibirité, município que faz parte da região metropolitana de Belo Horizonte. As turmas foram organizadas de modo a agrupar professores de uma mesma cidade ou região do Estado, coma finalidade de facilitar o contato entre eles após voltarem aos seus locais de origem.

No primeiro desses encontros começamos por discutir com os professores os pressupostos teóricos a que nos referimos anteriormente e a filosofia que estava por trás do processo de elaboração dos módulos. Após isso os professores faziam algumas das atividades constantes dos três módulos exemplares que havíamos elaborados previamente, discutindo não só aspectos do conteúdo químico mas também questões metodológicas relacionadas à elaboração dos módulos e à sua aplicação em sala de aula. Paralelamente a essas atividades e ao longo de toda a semana, os professores deveriam, em grupo, escolher um dos temas propostos para compor o currículo e iniciar a elaboração de um módulo didático sobre esse tema. Para esse trabalho, os professores poderiam consultar uma gama variada de materiais didáticos, alternativos ou não, livros paradidáticos, enciclopédias, revistas especializadas, revistas de divulgação científica, etc. Esse material havia sido selecionado por nossa equipe e colocado à disposição dos professores em uma mini biblioteca na sala de aula. Ao final da semana acontecia uma avaliação de todo o processo, e ao mesmo tempo procurávamos ler o 
material produzido pelos professores e orientar a continuidade do trabalho. Esse conjunto de atividades foi desenvolvido em colaboração com uma equipe de professores universitários e do Ensino Médio que tem trabalhado conosco em outros projetos de formação continuada.

Os Encontros posteriores (o segundo e o terceiro) aconteceram aproximadamente em intervalos de 4 meses e tiveram a mesma estrutura básica. A diferença é que começávamos por uma avaliação dos resultados do uso dos módulos, propostos ou por eles elaborados, nas suas salas de aula e por uma discussão das dificuldades de operacionalização da proposta curricular. No terceiro encontro a parte de produção de módulos foi substituída por discussões de questões metodológicas como avaliação, elaboração de provas e uso de ferramenta tecnológicas, como computadores e vídeo, no ensino de química. Essa mudança procurou atender a demanda dos próprios professores, explicitada no segundo encontro.

Apesar de inúmeras limitações que procuraremos apontar nas considerações finais, avaliamos que o processo descrito constitui um avanço em relação à maioria das propostas de reformulação curricular já formuladas, principalmente por tentar fazer do professor um sujeito dessa mudança e não um simples consumidor de pacotes desenvolvidos por especialistas.

A seguir procuraremos discutir algumas características dos currículos tradicionais propostos para o Ensino de Química em nível médio. É importante ressaltar que existem, no Brasil, várias tentativas de implementar propostas alternativas para ensinar química. Além disso, muitos professores que usam os currículos mais tradicionais tentam introduzir inovações no ensino de vários conteúdos previstos nestes currículos. Portanto, ao nos referirmos ao "currículo tradicional de química" estamos nos referindo a uma aproximação idealizada do que acontece realmente nas salas de aula de química. Apesar dos riscos que essa aproximação representa, julgamos imprescindível fazer uma crítica aos pressupostos, na maioria das vezes não explícitos, que orientam esses currículos, pois eles caracterizam a maior parte dos textos didáticos, destinados ao Ensino Médio de Química, encontrados no mercado.

\section{CARACTERIZANDO O ENSINO MÉDIO DE QUÍMICA ATUAL}

Vivemos em uma época na qual tem sido muito comum o uso de materiais sofisticados, destinados a atividades cada vez mais específicas. A sociedade tecnológica exige das ciências dos materiais respostas precisas e específicas às suas demandas. A Química, ciência central na concepção de novos materiais, pode oferecer respostas a essa diversidade de demandas, através do conhecimento sobre a constituição, propriedades e transformações das substâncias. Entretanto, a produção e a utilização dos materiais têm provocado diversos problemas ambientais. Essa é uma preocupação recente e representa um desafio também para os químicos.

A proposta curricular de Química para o Ensino Médio do Estado de Minas Gerais, que iremos discutir, busca contemplar aspectos conceituais que permitam a compreensão da constituição, propriedades e transformações dos materiais, destacando as implicações sociais relacionadas à sua produção e a seu uso.

Os currículos tradicionais têm enfatizado, na maioria das vezes, apenas aspectos conceituais da química, apoiados numa tendência que vem transformando a cultura química escolar em algo completamente descolado de suas origens científicas e de qualquer contexto social ou tecnológico. Além disso, esses currículos apresentam um número excessivo de conceitos, cuja interrelação é dificilmente percebida pelos alunos. A quantidade de conceitos - ou definições? - e procedimentos que são introduzidos a cada aula, a cada página da maioria dos livros didáticos, é muito grande para que seja possível ao aluno, em tão pouco tempo, compreende-los e ligá-los logicamente numa estrutura mais ampla que dê significado à aprendizagem da química. Aos alunos fica a impressão de se tratar de uma ciência totalmente desvinculada da realidade, que requer mais memória do que o estabelecimento de relações.

Na maioria desses currículos, os conceitos são confundidos com definições, que o aluno passa a usar de maneira mecânica em problemas de tipos bem determinados. O conceito de densidade, por exemplo, é introduzido, na maioria dos livros utilizados no Ensino Médio, através de uma única linha em que se apresenta a fórmula da densidade, como $\mathrm{d}=\mathrm{m} / \mathrm{v}$. A seguir, sugerem-se exercícios envolvendo a aplicação direta dessa fórmula, nos quais os valores de duas das variáveis são fornecidos, bastando usar a fórmula para se encontrar o valor da terceira. Quando solicitamos ao aluno, que "aprendeu" densidade por esse processo, que explique o funcionamento dos densímetros, usados em postos de gasolina para determinar se o álcool vendido como combustível está dentro das especificações, descobrimos que, na maioria das vezes, ele não é capaz de reconhecer neste um problema que possa ser resolvido usando o "conceito" de densidade. Na verdade esse aluno não aprendeu um conceito mas apenas sua definição, já que um conceito implica ao mesmo tempo a relação com objetos e com outros conceitos. Aprender a usar a definição de densidade não implica na aprendizagem do conceito, uma vez que essa só será possível após a aplicação do conceito a diferentes fenômenos, nos quais as relações entre densidade e outros conceitos vai se tornando explícita.

Qual a visão de aprendizagem subjacente aos currículos que enfatizam o ensino de conceitos? É possível a aprendizagem de conceitos como "átomos conceituais" em estruturas complexas, relacionadas logicamente, mas sem relação com os contextos em que essa estrutura foi criada e é utilizada? É possível separar contexto, conteúdo, objetivos e processos usados na aprendizagem de um conceito científico? Se a aprendizagem é vista como dependente da interação entre estrutura conceitual e contexto, é possível pensar uma estrutura conceitual mínima que orientaria o currículo? Por que essa estrutura permanece oculta na maioria dos currículos e textos didáticos tradicionais?

Nosso ensino de química tradicional é fruto, na maioria das vezes, de um processo histórico de repetição de fórmulas que são bem sucedidas do ponto de vista didático - fazer com que o aluno aprenda alguns procedimentos relacionados à Química, transformando a disciplina num manejo de pequenos rituais. Contraditoriamente, essa tendência foi aprofundada pela reformulação curricular da década de 60 , em que a abordagem descritiva foi substituída por outra mais teórica. As teorias introduzidas, que tinham por objetivo unificar diversos fenômenos antes tratados separadamente, produziram, inicialmente, uma abordagem mais coerente e a década de 60 foi rica em tentativas de se aprofundar essa tendência. No entanto, todas essas tentativas sucumbiram à tendência tecnicista da década de 70, quando o que determinava a escolha dos conteúdos era a possibilidade de que pudessem ser transformados em questões objetivas de testes de múltipla escolha. Esse movimento acabou resultando no aprofundamento da tendência classificatória e ritualística no ensino de química, desta vez sob nova roupagem, mais teórica e menos descritiva. Distribuir elétrons - ou será melhor chamá-los de setinhas - por níveis, subníveis e orbitais; classificar cadeias carbônicas, substâncias simples e compostas, isômeros, ligações químicas. Estes são apenas uns poucos exemplos desses rituais, que muitas vezes se resumem a relacionar entre si aspectos formais da química - como fórmulas e classificações. Ao aluno resta tentar achar algum fio oculto que possa desatar esse emaranhado de definições, classificações e fórmulas.

A repetição acrítica de fórmulas didáticas, que dão resultado, acaba por transformar a Química escolar em algo cada vez mais distante da ciência química e de suas aplicações na sociedade. Nossa química escolar se alimenta principalmente da 
tradição, o que explica, por exemplo, que se encontre conceitos e sistemas classificação semelhantes em livros de 1830 e nos atuais. Um exemplo é a classificação das reações (ou equações?) químicas em dupla troca, simples troca ou deslocamento, etc. Esse sistema se baseia no dualismo eletroquímico de Berzelius (1812), que propunha que as substâncias resultavam da combinação entre pares de espécies em que uma é eletricamente positiva e a outra negativa ${ }^{2}$. As reações de dupla troca $(\mathrm{AB}+\mathrm{CD}=\mathrm{AD}+\mathrm{CB})$ e de deslocamento $(\mathrm{AB}+\mathrm{C}=\mathrm{CB}+\mathrm{A})$, ocorreriam porque um radical mais eletropositivo deslocaria $\mathrm{o}$ radical menos eletropositivo. Já a partir da teoria de dissociação eletroquímica de Arrhenius (1883), as reações em meio aquoso não poderiam mais ser pensadas com dupla troca ou deslocamento, já que todas as espécies em solução estariam dissociadas e não haveria trocas ou deslocamentos, mas combinações entre íons para formar, por exemplo, sais pouco solúveis. Por exemplo, ao representarmos a equação

$$
\mathrm{Pb}\left(\mathrm{NO}_{3}\right)_{2}(\mathrm{aq})+2 \mathrm{KI}(\mathrm{aq}) \rightarrow \mathrm{PbI}_{2}(\mathrm{~s})+2 \mathrm{KNO}_{3}(\mathrm{aq})
$$

pelas espécies iônicas que realmente existem em solução,

$\mathrm{Pb}^{2+}(\mathrm{aq})+2 \mathrm{NO}_{3}^{-}(\mathrm{aq})+2 \mathrm{~K}^{+}+2 \mathrm{I}^{-}(\mathrm{aq}) \rightarrow \mathrm{PbI}_{2}(\mathrm{~s})+2 \mathrm{~K}^{+}(\mathrm{aq})$ $+2 \mathrm{NO}_{3}^{-}(\mathrm{aq})$,

desaparece a ilusão da dupla troca, pois os íons potássio e nitrato nem participam da reação e sim permanecem em solução aquosa. A reação poderia ser representada simplesmente por:

$$
\mathrm{Pb}^{2+}(\mathrm{aq})+2 \mathrm{I}^{-}(\mathrm{aq}) \rightarrow \mathrm{PbI}_{2}(\mathrm{~s}) .
$$

Ao tratar a química unicamente do ponto de vista formal, o ensino tradicional deixa de lado os fenômenos reais. Nessa química de quadro negro tudo é possível, desde a reação entre dióxido de carbono e água para formar ácido carbônico (que ocorre apenas em pequenas proporções nas condições atmosféricas) até a "reação" entre dióxido de silício e água, para formar ácido silícico, que, se ocorresse nas condições atmosféricas, levaria a crosta terrestre, formada principalmente por silicatos, literalmente por água abaixo.

Ao lado dessas classificações obsoletas permanecem outras sem nenhuma aplicação científica ou tecnológica, como a classificação de pares de espécies atômicas como isóbaros ou isótonos. A esses exemplos somam-se inúmeros outros, presentes no ensino de química, em que regras práticas, como a do octeto, a de distribuição eletrônica, ou ainda as regras para se determinar os números quânticos de um determinado elétron, passam a ocupar o lugar dos princípios químicos que lhes deram origem. Aqui cabe a distinção entre conhecimento ritu$a l$, ou de procedimentos, e o conhecimento de princípios $^{3}$. Conhecimento ritual é um tipo particular de conhecimento relacionado aos procedimentos, ao saber fazer alguma coisa. O conhecimento de princípios é essencialmente explicativo, orientado para o entendimento de como os procedimentos e os processos funcionam, porque certas conclusões são válidas e necessárias. Em muitos contextos, obviamente os procedimentos são inteiramente adequados e necessários. Os procedimentos se tornam rituais quando passam a ser um substituto para o entendimento dos princípios subjacentes. Parece-nos que isso é exatamente o que está ocorrendo com vários tópicos no ensino de química. No caso particular da regra do octeto, por exemplo, esse procedimento útil para a previsão da valência e das fórmulas de compostos de elementos típicos da tabela periódica se transforma num ritual, um verdadeiro dogma para explicar a estabilidade dos compostos químicos, substituindo princípios mais gerais como as variações de energia envolvidas na formação de ligações entre os átomos. Esse e outros fatos contribuem para aprofundar a má fama da Química, entre os estudantes do Ensino Médio: algo desinteressante e sem sentido, que apenas exige esforço de memória.

\section{A PROPOSTA CURRICULAR DE QUímiCA PARA O ENSINO MÉDIO EM MINAS GERAIS}

Esta proposta busca abordar apenas alguns conceitos fundamentais, mostrando a sua interrelação e sua aplicação a problemas sociais e tecnológicos. O currículo está organizado possibilitando uma interação entre o discurso científico da Química e o discurso cotidiano. Mas, para que isso aconteça é preciso que o discurso científico faça sentido para o aluno. Isso poderia ser alcançado tanto problematizando suas idéias informais quanto criando contextos que sejam significativos para ele.

Para um currículo contemplar o pensamento do aluno e os contextos de significação, além de promover o desenvolvimento dos conceitos científicos em si, é necessário que ele seja bem dimensionado em relação à quantidade de conceitos a serem abordados. Um currículo que apresente uma estrutura conceitual carregada, como é o caso dos currículos tradicionais, tem como pressuposto que aprender Química é somente aprender o conteúdo químico.

O currículos tradicionais, ao abordarem apenas aspectos conceituais da Química, têm como pressuposto que a aprendizagem de estruturas conceituais antecede qualquer possibilidade de aplicação dos conhecimentos químicos. Além disso, supõe-se que a abordagem desses conceitos deva ser exaustiva. Por exemplo, o conceito de molécula só poderia ser introduzido quando se esgotasse o ensino do conceito átomo, tendo-se abordado todos os modelos atômicos, inclusive o atual. Dessa forma, há uma cadeia linear de pré-requisitos que deve ser seguida.

O pressuposto de que se deva, no ensino, esgotar um conceito para poder aplicá-lo pode ser questionado, pois é justamente nas aplicações do conceito que se explicitarão as relações a serem estabelecidas entre os conceitos. Além disso, existem tendências na psicologia contemporânea que consideram os conceitos inseparáveis dos contextos de aplicação, uma vez que o aluno tende a recuperar conceitos a partir desses contextos de aplicação e não no vazio ${ }^{4}$. Nesse sentido, nossa proposta procura abordar os conceitos químicos diretamente relacionados aos contextos de aplicação. Para cada tema duas instâncias de abordagem estarão presentes: a conceitual e a contextual. O objetivo é promover uma tensão dialética, no sentido de que, se um tema for predominantemente conceitual, de certa forma, é o conceito que organiza a estrutura de abordagem. Se o tema é mais contextual é o contexto que organiza os desdobramentos conceituais.

Para que isso seja possível, é necessário eleger alguns grandes temas que orientarão a seleção dos conceitos mais relevantes. Na presente proposta, esses temas são as propriedades, a constituição e as transformações dos materiais e substâncias.

A abordagem de conceitos ligados aos contextos de aplicação, como estamos propondo, não necessariamente precisa seguir uma cadeia linear de pré-requisitos, pois a realidade não se estrutura dessa maneira. Os conceitos podem ser abordados em diferentes momentos e níveis de profundidade. A exemplo dos golfinhos no oceano, os conceitos emergem, submergem e emergem novamente em diferentes momentos do curso. Esse movimento vai assegurar um aprofundamento progressivo, mais próximo à realidade dos fenômenos e das aplicações da Química.

Esses princípios se traduzem, nesta proposta, numa abordagem dos conceitos mais horizontal e qualitativa no primeiro ano, e numa verticalização e aprofundamento no segundo e terceiro anos. Isso significa que, no primeiro ano, os alunos discutirão temas que envolvem a compreensão de princípios fundamentais da química com uma ênfase qualitativa, tendo em vista prover uma base para o aprofundamento tanto dos conceitos como das aplicações. No segundo e no terceiro anos propomos um aprofundamento do estudo de temas químicos, incluindo aspectos quantitativos.

Os currículos tradicionais enfatizam classificações que se baseiam na idéia de que os conceitos podem ser definidos através 
de atributos essenciais e acessórios. Segundo essa lógica, um determinado conceito pertence a uma classe se compartilha, com todos os membros dessa classe, os mesmos atributos essenciais. Assim, todos os fenóis compartilham o fato de possuírem um grupo hidroxila ( - $\mathrm{OH}$ ) ligado ao anel de benzeno. Esses são os atributos essenciais da classe "fenóis". Através dessa lógica, classificam-se as ligações em iônicas, covalentes e metálicas; as substâncias em simples e compostas; as reações em dupla troca, simples troca, decomposição e síntese etc. Os currículos tradicionais assumem que essas classificações são, de certa forma, absolutas e fundamentais para a aprendizagem da Química. Essa lógica omite uma importante característica de muitos conceitos, que é particularmente importante na Química: os conceitos são relacionais ${ }^{5}$. Isso significa que, para esses conceitos relacionais, os atributos de um sistema não existem em si, mas em relação a um outro com o qual interage.

Por exemplo, no conceito de oxiredução, uma espécie é oxidante em relação a outra. Não existe conceito na química que respalda uma afirmação do tipo essa substância é redutora. Isto é ácido, isto é base são também exemplos dessa consideração. Um é oxidante em relação a outro que se comporta como redutor. Um é ácido em relação a outro que se comporta como base. A tendência dos currículos tradicionais é afirmar isto é ácido, isto é redutor, isto é base, o que retira completamente esse caráter relacional.

$\mathrm{Na}$ Química existe uma quantidade muito grande de conceitos que são categorias superordenadas (matéria, substância, átomo, por exemplo), o que explica a predominância de um tratamento atributivo dos conceitos químicos nos currículos tradicionais. Quando se aborda o conceitos ácido, por exemplo, logo se segue uma série de propriedades dos ácidos, tipos de ácidos etc. Isso se deve ao caráter atributivo que os currículos tradicionais dão ao conceito ácido: ácidos corróem metais, ácidos produzem hidrogênio na reação com metais. Dessa maneira, são geradas redes de classificação e dicotomias na abordagem dos conceitos. No entanto, mesmo ácidos minerais fortes, considerados como "o" exemplo de ácidos (ácido clorídrico e sulfúrico) podem se comportar como bases frente a certas substâncias conhecidas como superácidos ${ }^{6}$.

Em vista do exposto, é importante evitar o excesso de esquemas classificatórios na configuração de um novo currículo, embora se reconheça a existência e a importância da superordenação entre os conceitos. Contudo ela não pode esconder o caráter relacional dos conceitos químicos. Além disso, deve-se destacar que a fronteira entre certas classes não é rígida. Assim, uma ligação covalente pode apresentar um certo caráter iônico, e a maioria das ligações se situa em algum ponto entre um caráter puramente iônico e outro puramente covalente.

Para avançar na formulação de um currículo que atenda às demandas atuais da sociedade, é importante repensar muitas dessas visões que estiveram sustentadas em pressupostos atualmente superados. Duas razões fortes para nos conduzir a essa reflexão: a própria ciência está superando essa abordagem cartesiana da estruturação superordenada dos conteúdos. A exigência curricular, com a qual concordamos - preparar o cidadão para a vida, para o trabalho e para continuar a aprender - impõenos esse diálogo. Ao promovermos o diálogo temos, obrigatoriamente, que ir além essa categorização, porquanto ela é externa ao aluno. E, se queremos atender a demandas dos alunos, é fundamental pensar uma proposta segundo uma outra lógica.

Tudo isso fundamenta e justifica nossa proposta de temas de natureza mais abrangente, a partir dos quais pode-se derivar questões conceituais e contextuais e o reaparecimento do mesmo tema em séries diferentes. Na lógica da linearidade do currículo tradicional não existe essa recorrência.

\section{SELEÇÃO E ORGANIZAÇÃo DE CONTEÚDOS}

A química tem como objetos de investigação os materiais as substâncias, suas propriedades, sua constituição e suas transformações. No centro de todas essas investigações certamente encontram-se os materiais e as substâncias. O triângulo (Triângulo 1) a seguir representa as interrelações entre os objetos e focos de interesse da química.

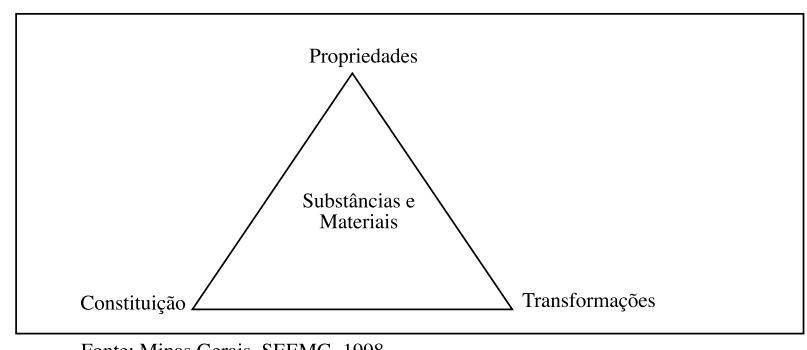

Fonte: Minas Gerais. SEEMG, 1998

Triângulo 1. Focos de interesse da química.

Este triângulo aponta para algumas considerações interessantes no que diz respeito aos temas do conteúdo químico a serem destacados.

O conhecimento das substâncias e dos materiais diz respeito a suas propriedades, tais como dureza, ductibilidade, temperaturas de fusão e ebulição, solubilidade, densidade e outras passíveis de serem medidas e que possuem uma relação direta com o uso que se faz dos materiais. No sentido de compreender os comportamentos dos materiais alguns conhecimentos químicos são fundamentais: aqueles que envolvem os diversos modelos que constituem o mundo atômico-molecular, as propostas para conceber a organização e as interações entre átomos, íons e moléculas. Esses conhecimentos oferecem subsídios importantes para a compreensão, o planejamento, a execução das transformações dos materiais. Estabelecer interrelações entre esses três aspectos nos parece fundamental para que se possa compreender vários tópicos de conteúdo químico.

Se formos considerar os currículos e livros didáticos de química mais utilizados no Brasil poderemos constatar que, em geral, os tópicos do conteúdo selecionados são os mesmos do nosso triângulo. Nos currículos tradicionais estes conceitos são abordados em uma seqüência linear. Em nossa proposta consideramos fundamental a interrelação constante entre esses vértices do triângulo.

É possível aprofundarmos um pouco esta análise focalizando agora formas de abordagens. Para cada um desses conteúdos poderíamos então utilizar um referencial que nos permitisse analisar as diversas possibilidades de abordagem. Do ponto de vista didático, é útil distinguir três aspectos do conhecimento químico: fenomenológico, teórico e representacional.

$\mathrm{O}$ aspecto fenomenológico diz respeito aos fenômenos de interesse da química, sejam aqueles concretos e visíveis, como a mudança de estado físico de uma substância, sejam aqueles a que temos acesso apenas indiretamente, como as interações radiaçãomatéria que não provocam um efeito visível mas que podem ser detectadas na espectroscopia. Os fenômenos da química também não se limitam àqueles que podem ser reproduzidos em laboratório. Falar sobre o supermercado, sobre o posto de gasolina é também uma recorrência fenomenológica. Neste caso, o fenômeno está materializado na atividade social. E é isso que vai dar significação para a Química do ponto de vista do aluno. São as relações sociais que ele estabelece através dessa ciência que mostram que a Química está na sociedade, no ambiente. A abordagem do ponto de vista fenomenológico também pode contribuir para promover habilidades específicas tais como controlar variáveis, medir, analisar resultados, elaborar gráficos etc.

$\mathrm{O}$ aspecto teórico relaciona-se a informações de natureza atômico-molecular, envolvendo, portanto, explicações baseadas em modelos abstratos e que incluem entidades não diretamente perceptíveis, como átomos, moléculas, íons, elétrons etc. 
Os conteúdos químicos de natureza simbólica estão agrupados no aspecto representacional, que compreende informações inerentes à linguagem química, como fórmulas e equações químicas, representações dos modelos, gráficos e equações matemáticas.

O triângulo apresentado a seguir (Triângulo 2) representa as interrelações entre esses aspectos do conhecimento químico.

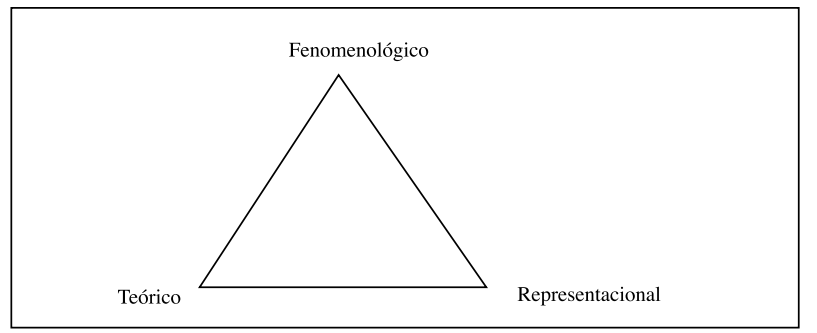

Fonte: Minas Gerais. SEEMG, 1998

Triângulo 2. Aspectos do conhecimento químico.

A maioria dos currículos tradicionais e dos livros didáticos, enfatiza sobremaneira o aspecto representacional, em detrimento dos outros dois. A ausência dos fenômenos nas salas de aula pode fazer com que os alunos tomem por "reais" as fórmulas das substâncias, as equações químicas e os modelos para a matéria. É necessário, portanto, que os três aspectos compareçam igualmente. A produção de conhecimento em Química resulta sempre de uma dialética entre teoria e experimento, pensamento e realidade. Mesmo porque não existe uma atividade experimental sem uma possibilidade de interpretação. Ainda que o aluno não conheça a teoria científica necessária para interpretar determinado fenômeno ou resultado experimental, ele o fará com suas próprias teorias implícitas, suas idéias de senso comum, pois todo processo de compreensão é ativo ${ }^{7}$. Para que a interpretação do fenômeno ou resultado experimental faça sentido para o aluno, é desejável manter essa tensão entre teoria e experimento, percorrendo constantemente o caminho de ida e volta entre os dois aspectos. O aspecto representacional também resulta dessa tensão, fornecendo as ferramentas simbólicas para representar a compreensão resultante desses processos de idas e vindas entre teoria e experimento. É importante ressaltar que, nesta proposta, o conceito de fenômeno e de experimento ultrapassa a dimensão do laboratório. Ir ao supermercado, fazer uma visita, investigar a corrosão do portão da garagem, também são atividades que se caracterizam pela ação de experienciar, vivenciar, em geral de forma sistematizada. No caso das atividades de laboratório, são desenvolvidas habilidades específicas como as já citadas - controlar variáveis, organizar dados em tabelas e construir gráficos etc. Um experimento pode cumprir também o papel de mostrar essa forma de pensar em química, em que teoria e realidade estão em constante interlocução. $\mathrm{O}$ aluno pode ser levado a formular hipóteses, desenvolver formas de testá-las, modificá-las de acordo com os resultados etc. No caso das demais atividades, o aluno tem oportunidade de desenvolver essas mesmas habilidades e outras, como por exemplo experienciar a forma como os conceitos químicos estão funcionando nas relações sociais, inclusive como mediadores dessas relações.

A visão da Química como atividade hipotético-dedutiva privilegia os aspectos citados acima, como formular e testar hipóteses. Estudos em sociologia da ciência revelam, no entanto, que o cerne da prática científica cotidiana é a resolução de problemas abertos. Ao encaminhar a solução de determinada questão, o cientista vai deparando-se com uma série de outros problemas. Um problema aberto não tem uma solução única e demanda do cientista avaliações constantes de custo e benefício, de riscos e de escolha de caminhos alternativos. $\mathrm{Na}$ abordagem por resolução de problemas a intuição desempenha um papel fundamental nas tomadas de decisão. Esse aspecto pode ser uma ferramenta importante para o aluno em todos os setores da atividade produtiva, e não apenas naqueles ligados à Química.

$\mathrm{O}$ enfoque contextual sugerido nesta proposta curricular pretende privilegiar a resolução de problemas abertos, nos quais o aluno deverá considerar não só aspectos técnicos como também sociais, políticos, econômicos e ambientais, o que resulta numa demanda por abordagens interdisciplinares no Ensino Médio. Nossa preocupação, ao ressaltar esses aspectos, não é formar mini-cientistas, mas cidadãos. A Química pode fornecer ao aluno instrumentos de leitura do mundo e, ao mesmo tempo, desenvolver certas habilidades básicas para ele viver em sociedade.

\section{TEMAS PROPOSTOS}

Os temas sugeridos para os três anos do Ensino Médio procuram concretizar as idéias discutidas no texto introdutório. Os aspectos conceituais e contextuais estão mesclados ao longo do programa. O professor não deve ter a preocupação de trabalhar com todos os temas relacionados. A idéia é ele possa compor seu currículo a partir desses temas, adaptando suas escolhas às suas preferências e condições de trabalho. Mesmo dentro de um tema, o professor não precisa necessariamente esgotar todos os assuntos propostos. Essa flexibilidade permitirá que o professor possa elaborar um currículo que tem por eixo temas conceituais ou, se preferir, temas contextuais. É importante ressaltar, que a escolha de um ou outro eixo não implica na ausência do outro.

Os temas sugeridos para o primeiro ano configuram um conjunto de conceitos básicos, em torno dos três focos de interesse da Química - propriedades, transformações e constituição dos materiais e substâncias. Esses temas serão aprofundados no segundo ano. Para o terceiro ano, tivemos a preocupação de relacionar temas que contemplam as principais atividades produtivas desenvolvidas no Estado de Minas Gerais, de modo a possibilitar que o aluno tenha contato com uma leitura química das atividades predominantes em sua região. Essa preocupação está presente também nas orientações do Ministério da Educação e dos Desportos, que recomenda que o currículo deva enfatizar as capacidades de aprender a aprender e preparar o aluno para o exercício da cidadania e para o trabalho

Para exemplificar possíveis desenhos curriculares a partir dos temas propostos, depois de sua apresentação relacionamos duas configurações do currículo de primeiro e segundo ano: uma delas tem por eixo os conceitos, e lista os temas contextuais que poderão ser trabalhados a partir dos conceitos apresentados; a outra tem por eixo os contextos sociais, ambientais e tecnológicos, e lista as principais idéias e conceitos relacionados aos temas escolhidos.

Não fizemos esse exercício em relação ao terceiro ano por julgar que a organização curricular para essa série tem que se pautar pelas atividades econômicas da região de atuação do professor.

\section{TEMAS PARA O $1^{\circ}$ ANO}

1) Propriedades dos Materiais: Densidade

2) Propriedades dos Materiais: Temperaturas de Fusão e de Ebulição

3) Propriedades dos Materiais: Solubilidade

4) Modelo Cinético-Molecular e as propriedades dos materiais

5) Materiais: misturas, substâncias simples e compostas

6) Tratamento de água para consumo urbano

7) Lixo Urbano: descarte e reciclagem de materiais

8) Propriedades elétricas dos materiais e o modelo atômico de Rutherford

9) Propriedades dos metais e o modelo de ligação metálica

10) Obtenção de metais: mineração e metalurgia

11) Corrosão de metais: transformações dos materiais

12) Transformações químicas: formação de novos materiais 
13) Transformações químicas: conservação da massa e sua relação com as representações das reações químicas por equações.

14) Problemas na atmosfera: efeito estufa e buraco na camada de ozônio

15) Transformações químicas: obtendo e dispendendo energia

16) Combustíveis: carvão, derivados de petróleo e álcool

17) Obtendo energia dos alimentos

18) Transformações químicas: controlando a rapidez das reações químicas

19) Conservação de alimentos

20) Espectro eletromagnético

21) Modelo atômico de Bohr: emissão de luz por substâncias vaporizadas numa chama como evidência para a quantização das energias dos elétrons

22) Radiações: riscos e benefícios

23) Propriedades dos materiais e o modelo de ligação iônica

24) Cerâmicas: novos e velhos materiais

25) Propriedades dos materiais e o modelo de ligação covalente

26) Polímeros

27) Condutividade elétrica em substâncias e soluções: elétrons em movimento, íons em movimento; modelos de ligação química para explicar os vários fenômenos. Polímeros e cerâmicas condutoras

\section{TEMAS PARA O $2^{\circ}$ ANO}

1) Soluções: constituição, modelos; a natureza das espécies em solução; concentração

2) Soluções no supermercado: agentes de limpeza; constituição e concentração.

3) Soluções na farmácia: aquosa, alcóolica; concentração e constituição.

4) Quantidades em Química: a unidade de quantidade de matéria (mol); as relações entre quantidades numa equação química; concentração em quantidade de matéria (mol/L); balanceamento de equações por tentativa; reagente limitante.

5) Termoquímica: calor e temperatura; Introdução aos fenômenos energéticos relevantes para a química.

6) Termoquímica: Combustíveis fósseis: calor de combustão; lei de Hess; Produção de $\mathrm{CO}_{2}$ e efeito estufa.

7) Termoquímica: o etanol com combustível: obtenção de energia a partir da queima do álcool (calor de combustão); comparação com outros combustíveis; o impacto ambiental da produção e da queima do álcool (vinhoto, o efeito estufa).

8) Termoquímica: produção de energia a partir de alimentos; valor energético dos alimentos e dietas ricas e pobres em calorias; calor de combustão de alimentos; queima de alimentos dentro e fora do corpo humano - o papel das enzimas no metabolismo humano.

9) Termoquímica: produção de metais a partir de minérios; obtenção de ferro a partir do minério e da reciclagem comparação dos custos energéticos.

10) A água e a circulação de energia no planeta: evaporação e condensação da água em diferentes regiões; calor específico e capacidade calorífica da água; calor de vaporização e de condensação da água; correntes marítimas e o clima da Terra.

11) Fontes alternativas de energia: energia solar; funcionamento de uma bateria solar; energia solar e aquecimento de água; energia eólica; produção de gás a partir de biomassa.

12) Energia nuclear: decaimento radioativo; vida média de radionuclídeos; ciclo do combustível nuclear; funcionamento de uma usina nuclear.

13) Energia nuclear: lixo atômico; problemas ambientais; vantagem e desvantagens do uso de energia nuclear.

14) Gases: relações entre pressão, volume e temperatura para sistemas gasosos; a teoria cinético-molecular e o comportamento dos gases;

15) Gases: reações químicas envolvendo gases em sistemas abertos e fechados - ferrugem, combustão, calcinação de metais.
16) Oxidação e redução: movimento de elétrons. Introdução aos fenômenos de oxidação e redução.

17) Oxidação e redução: o oxigênio - ocorrência, propriedades físicas e químicas; interações com os materiais.

18) Oxidação e redução : o oxigênio na fotossíntese e na respiração (carboidratos, ácidos carboxílicos, gorduras, açúcares).

19) Oxidação e redução: o hidrogênio - ocorrência, propriedades físicas e químicas; interações com os materiais.

20) Oxidação e redução: oxidantes e redutores mais comuns no cotidiano (anti-sépticos, branqueadores e removedores) e nas indústrias.

21) Radicais livres e o envelhecimento: processos de oxidação e redução; vitaminas.

22) Pilhas e células eletroquímicas: funcionamento de pilha comum e bateria de carro; proteção de metais por eletrodos de sacrifício.

23) Galvanoplastia: cromação, cobreamento, douração; pilhas e células eletroquímicas.

24) Pilhas e células eletroquímicas: obtenção de alumínio a partir do minério e da reciclagem - comparação do custo energético.

25) Comportamentos de substâncias: as várias visões históricas para ácidos e bases.

26) Equilíbrio Químico: uma introdução ao estado de equilíbrio químico

27) Equilíbrios ácido-base no corpo humano;

28) Ácidos e bases na saúde humana: antiácidos; fontes nos alimentos;

29) Equilíbrio iônico: sódio e potássio no organismo; reidratação e recomposição iônica do organismo; comércio de bebidas de esporte.

\section{TEMAS PARA O $3^{\circ}$ ANO}

1) Química na agricultura: fotossíntese; nutrição das plantas, nutrientes essenciais - nitrogênio, fósforo, potássio; outros elementos essenciais - magnésio, cálcio e enxofre; micronutrientes - boro, cobre, ferro, manganês, molibdênio, zinco, cloro; processos de correção dos solos - uso de fertilizantes; cuidados na utilização; ciclo biogeoquímico do carbono; impacto ambiental.

2) Química na agricultura: Pesticidas, herbicidas e desfolhantes - constituição química - ddt, organofosforados, carbamatos etc; legislação para o uso; riscos e consequiências de intoxicação; impacto ambiental; feromônios; controle biológico.

3) Química na pecuária: nutrição dos animais - composição e balanceamento de dietas; utilização de ração e capim; utilização de medicamentos para o combate a doenças; vacinas; produção de carne e leite.

4) Química e turismo: águas minerais - As várias "águas" da natureza: rios, mares, lagos, chuvas, lençóis freáticos, água potável, água dura, água salobra, água poluída - constituição e propriedades; água como solvente universal: ligações intramoleculares e intermoleculares; análise química de águas; impacto ambiental do turismo; possibilidades de contribuição da química para o gerenciamento de um turismo que respeite os conhecimentos locais.

5) Química e turismo: conservação do patrimônio histórico e cultural - papel; constituição, processos de produção, deterioração, conservação e recuperação; construções - materiais utilizados, processos de deterioração, conservação e recuperação; obras de arte - principais materiais utilizados; tintas e pigmentos; materiais para escultura, processos de deterioração, conservação e recuperação.

6) Química dos perfumes, aromas e sabores - cosméticos e alimentos; materiais de partida - ésteres, cetonas, aldeídos, aminas e álcoois constituição e propriedades físicas e químicas; extração, identificação e processos de separação; aspectos legais de sua utilização; papel da isomeria.

7) Química de alimentos: laticínios - materiais de partida, 
propriedades, constituição; processo de pasteurização; processos físicos e químicos envolvidos na produção e conservação de iogurtes e queijos controle de qualidade dos produtos.

8) Química de alimentos: pães - materiais de partida - água, farinha e fermento - constituição química, glicídios (amido), proteínas, enzimas; processos físicos e químicos envolvidos no amassamento, fermentação e cozimento - reações de fermentação; controle de qualidade dos produtos.

9) Química de alimentos: cachaça - Álcool Etílico: obtenção, constituição e propriedades físicas e químicas; outros álcoois; produção de bebidas alcóolicas: o álcool e o organismo humano; aspectos sociais do alcoolismo; controle de qualidade dos produtos.

10) Química de alimentos: doces e compotas - materiais de partida - constituição química, pectina, carboidratos, açúcares; processos químicos envolvidos na fabricação e conservação de doces e compotas; geléias - compostos gelificantes, processos de produção e conservação. Adoçantes substituindo o açúcar, aspartame, estévia, ciclamato e sacarina; relação entre o uso e abuso de adoçantes e açúcar na alimentação; controle de qualidade dos produtos.

11) Química dos cosméticos: shampoos e sabonetes - materiais de partida - constituição química, propriedades; processos de produção; controle de qualidade dos produtos; impactos ambientais associados à produção e descarte .

12) Química da siderurgia: materiais de partida - constituição química; processos de produção; aços especiais, impactos ambientais associados à produção e descarte; controle de qualidade dos produtos.

13) Química dos fertilizantes: materiais de partida - constituição química; processos de produção impacto ambiental; rejeitos industriais controle de qualidade dos produtos.

14) Química e a produção de calçados: materiais de partida - couro, processo de curtimento de peles. Borracha, constituição, processo de produção; impactos ambientais associados à produção e descarte.

15) Química e a construção civil: materiais principais - tijolos, cimento, plásticos, metais, vidro - constituição e propriedades; processos de produção; impactos ambientais associados à produção e descarte.

16) Química e os aspectos geológicos - pedras semi-preciosas: constituição química e estrutura; coloração natural e artificial.

17) Química e os aspectos geológicos: grutas - formação de grutas; ciclo biogeoquímico do carbono; equilíbrio de solubilidade.

18) Química do papel - materiais de partida, constituição química; processos de produção de polpa e de papel; impactos ambientais dos processos de produção e do uso de papéis; papéis especiais; controle de qualidade dos produtos.

19) A Química e o controle de qualidade dos produtos: técnicas para análise por via úmida - princípios fundamentais e aplicações; titulações; calcinações.

20) A Química e o controle de qualidade dos produtos: técnicas espectrométricas - princípios fundamentais e aplicações : absorção atômica, infravermelho, ultravioleta, raios $\mathrm{X}$, plasma, RMN, cromatografias.

21) A Química e a medicina: diagnóstico e as técnicas espectroscópicas raios $\mathrm{X}$, ressonância magnética nuclear; medicina nuclear e terapia por radioisótopos.

22) A Química e a medicina: medicamentos - anestésicos; sedativos; antitérmicos; vitaminas e complementos alimentares; medicamentos naturais e sintéticos.

23) A Química e as drogas - narcóticos e alcalóides - ópio, morfina, heroína, cocaína, tetrahidro canabinol (maconha), cafeína, nicotina; endorfinas; anfetaminas; uso lícito e o ilícito.

24) Química e agroindústria: produção de óleo de soja, produção de café solúvel

Sugestão para a composição de um currículo com eixo contextual

Primeiro Ano

Temas

Principais idéias e conceitos relacionados
Tratamento de água para consumo urbano ou Lixo Urbano: descarte e reciclagem de materiais

Obtenção de metais: mineração e metalurgia $\mathrm{Ou}$

Corrosão de metais: transformações dos materiais

Combustíveis: carvão, derivados de petróleo e álcool ou Obtendo energia dos alimentos ou

Problemas na atmosfera: efeito estufa e buraco na camada de ozônio
Propriedades: densidade, solubilidade, temperatura de fusão e ebulição

Transformações: processos de separação utilizados e sua relação com as propriedades dos materiais; processos físicos e químicos envolvidos.

Constituição: modelo atômico de Dalton. Utilização do modelo cinético molecular para representar a organização das partículas tendo em vista as propriedades apresentadas pelos materiais. Comparação de modelos relacionados à diferentes materiais. Modelos para as partículas constituintes de misturas. Modelos para substâncias simples e compostas.

Representação: representação das transformações envolvidas nos processo por equações químicas. Explicitação dos significados das representações. Fórmulas para substâncias simples e compostas possibilidade de diferenciação.

Nomenclatura e Tabela Periódica: localização dos principais elementos constituintes das substâncias envolvidas nos processos estudados. Explicitação dos nomes das substâncias e suas fórmulas.

Propriedades: metais - condutividade elétrica, ductibilidade, resistência.

Transformações: processos químicas envolvendo a formação de novos materiais; conservação da massa - rendimento dos processos; custos envolvidos.

Constituição: modelo atômico de Rutherford e sua relação com a condutividade elétrica de materiais; modelo de ligação metálica.

Representação: representação das transformações por equações químicas

Nomenclatura e Tabela Periódica: localização dos metais na tabela periódica. Características gerais desses elementos. Propriedades periódicas relacionadas.

Propriedades: mudança de propriedades com as transformações.

Constituição: composição do petróleo como mistura de substâncias; composição dos alimentos. Transformações: transformações químicas formação de novos materiais, conservação da massa e representação por equações químicas, obtendo e dispendendo energia.

Representação: representação das transformações por equações químicas.

Nomenclatura e Tabela Periódica: localização dos principais elementos constituintes das substâncias envolvidas nos processos estudados. Explicitação dos nomes das substâncias e suas fórmulas. 
Cont. Sugestão para a composição de um currículo com eixo contextual Primeiro Ano

Temas

Conservação de alimentos

Radiações: riscos e benefícios

Cerâmicas: novos e velhos materiais ou

Polímeros
Principais idéias e conceitos relacionados

Propriedades: evidências de deterioração dos alimentos.

Constituição: utilização do modelo cinético molecular para explicar os processos de conservação.

Transformações: transformações químicas e físicas envolvidas nos processos de deterioração e conservação dos alimentos; influências de fatores diversos no controle da rapidez das reações químicas.

Nomenclatura e Tabela Periódica: localização dos principais elementos constituintes das substâncias envolvidas nos processos estudados. Explicitação dos nomes das substâncias e suas fórmulas.

Propriedades: características das várias radiações ao interagirem com os materiais: cores, bronzeamento, cozimento de alimentos etc.

Constituição: espectro eletromagnético - relação com as ondas eletromagnéticas; modelo atômico de Bohr - emissão de luz por substâncias vaporizadas numa chama como evidência para a quantização das energias dos elétrons.

Transformações: interações da radiação com os materiais.

Nomenclatura e Tabela Periódica: energias de ionização como princípio básico para a compreensão da organização do elétrons em níveis de energia.

Propriedades: Condutividade elétrica em substâncias e soluções.

Constituição: modelos de ligação química para explicar os vários fenômenos: elétrons em movimento, íons em movimento.

Transformações: transformações envolvidas no processo de produção.

Nomenclatura e Tabela Periódica: localização dos principais elementos constituintes das substâncias envolvidas nos processos estudados. Explicitação dos nomes das substâncias e suas fórmulas.

Sugestão para a composição de um currículo com eixo conceitual

Primeiro Ano

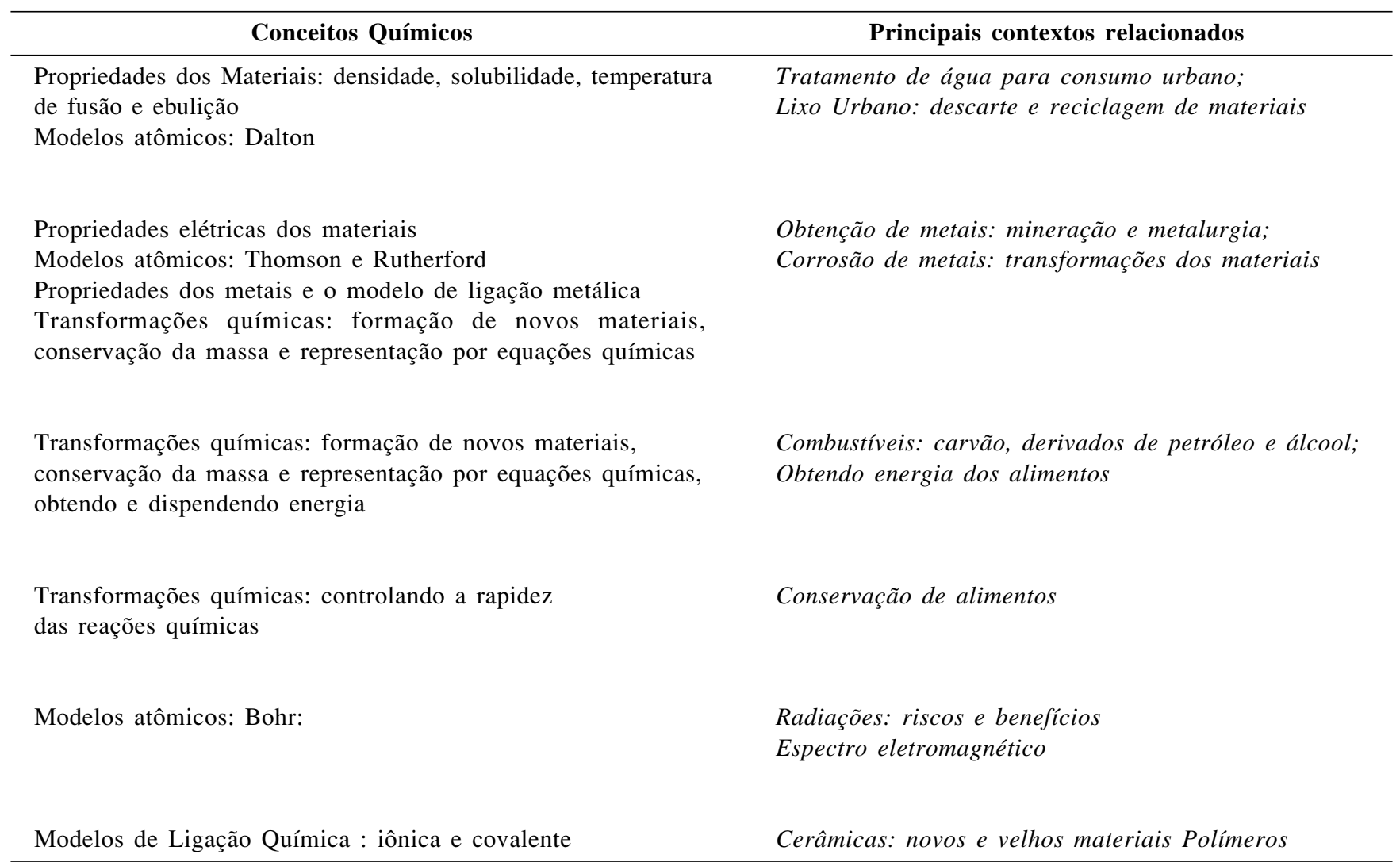


Sugestões para a composição de um currículo com eixo contextual Segundo Ano

Temas

Soluções no supermercado ou

Soluções na farmácia

\author{
Combustíveis fósseis \\ ou \\ Produção de energia a \\ partir de alimentos \\ ou \\ Produção de metais a \\ partir de minérios
}

A água e a circulação de energia no planeta

Fontes alternativas de energia

Energia nuclear

Antissépticos, branqueamento, remoção de manchas

ou

Radicais livres $e$

o envelhecimento

O oxigênio e o hidrogênio

ou

Fotossíntese e respiração
Principais idéias e conceitos relacionados

Propriedades: condutividade elétrica; reposição eletrolítica, propriedades detergentes.

Constituição: modelos para soluções; a natureza das espécies em solução (presença de íons, estrutura das partículas de água); interações soluto/solvente.

Nomenclatura e Tabela Periódica: localização dos principais elementos constituintes das substâncias envolvidas nos sistemas estudados. Explicitação dos nomes das substâncias e suas fórmulas.

Aspectos Quantitativos: a relação entre quantidades, cálculos de concentração percentual, $\mathrm{p} / \mathrm{p}, \mathrm{p} / \mathrm{v}$ e $\mathrm{g} / \mathrm{L}$.

Propriedades: principais características dos materiais utilizados como combustíveis. Constituição: modelos das principais substâncias componentes dos combustíveis.

Transformações: fenômenos energéticos relevantes para a química: calor e temperatura; obtenção de energia a partir da queima de combustíveis; comparação com outros combustíveis; o impacto ambiental da produção e da queima dos vários combustíveis. Produção de energia a partir de alimentos; valor energético dos alimentos e dietas ricas e pobres em calorias; calor de combustão de alimentos; queima de alimentos dentro e fora do corpo humano - o papel das enzimas no metabolismo humano. Obtenção de a partir do minério e da reciclagem - comparação dos custos energéticos.

Nomenclatura e Tabela Periódica: localização dos principais elementos constituintes das substâncias envolvidas nos processos estudados. Explicitação dos nomes das substâncias e suas fórmulas.

Aspectos Quantitativos: cálculos de calor de combustão; lei de Hess.

Propriedades: água como solvente; propriedades importantes da água do ponto de vista energético: calor específico e capacidade calorífica; calor de vaporização e de condensação. Relação das propriedades com a circulação de energia no planeta, correntes marítimas e o clima da Terra.

Constituição: Modelos para a estrutura da água nos diversos estados físicos e sua relação com as propriedades por ela apresentadas.

Transformações: evaporação e condensação da água em diferentes regiões.

Aspectos Quantitativos: cálculos de calor específico, capacidade calorífica, calor de vaporização e de condensação.

Propriedades: Capacidade de produção de energia

Transformações: transformações envolvidas na utilização de fontes alternativas de energia; energia solar; funcionamento de uma bateria solar; energia solar e aquecimento de água; energia eólica; produção de gás a partir de biomassa.

Propriedades: fenômenos radioativos

Constituição: modelos para o átomo que considerem o núcleo como constituído por partículas. Transformações: transformações nucleares, comparação com os fenômenos da eletrosfera; decaimento radioativo:; vida média de radionuclídeos; ciclo do combustível nuclear; funcionamento de uma usina nuclear. lixo atômico; problemas ambientais; vantagem e desvantagens do uso de energia nuclear.

Nomenclatura e Tabela Periódica: localização dos principais elementos que constituem substâncias radioativas.

Propriedades: branqueamento,

Constituição: modelos para as partículas dos materiais envolvidos.

Transformações movimento de elétrons. Reações de oxidação e redução.

Nomenclatura e Tabela Periódica: localização dos principais elementos constituintes das substâncias envolvidas nos processos estudados. Explicitação dos nomes das substâncias e suas fórmulas.

Propriedades: pressão, volume e temperatura para sistemas gasosos; o oxigênio e o hidrogênio ocorrência, propriedades físicas e químicas;

Constituição: a teoria cinético-molecular e o comportamento dos gases

Transformações: reações químicas envolvendo gases em sistemas abertos e fechados - ferrugem, combustão, calcinação de metais. Fenômenos de oxidação e redução: interações do oxigênio e do hidrogênio com os materiais. $O$ oxigênio na fotossíntese e na respiração - carboidratos, ácidos carboxílicos, gorduras, açúcares.

Nomenclatura e Tabela Periódica: localização dos principais elementos constituintes das substâncias envolvidas nos processos estudados. Explicitação dos nomes das substâncias e suas fórmulas.

Aspectos Quantitativos: balanceamento de equações de oxiredução. 


\begin{tabular}{ll}
\hline \multicolumn{1}{c}{ Temas } & \multicolumn{1}{c}{ Principais idéias e conceitos relacionados } \\
\hline & Propriedades: condutividade elétrica, deposição de metais, desgaste de peças. \\
& Constituição: modelos para a representação do funcionamento de pilhas e células eletroquímicas. \\
& Transformações: cromação, cobreamento, douração; funcionamento de pilha comum e \\
bateria de carro; proteção de metais por eletrodos de sacrifício. & Nomenclatura e Tabela Periódica: localização dos metais na tabela periódica. Características \\
Galvanoplastia & gerais de substâncias elementares formadas por átomos desses elementos. Propriedades periódicas \\
ou & relacionadas movimento de elétrons. Introdução aos fenômenos de oxidação e redução \\
Obtenção de alumínio & Aspectos Quantitativos: balanceamento de equações de oxiredução; cálculos envolvendo \\
& massa de substâncias depositadas e desgastadas; cálculos de forças eletromotrizes das pilhas \\
& e células eletroquímicas. comparação do custo energético para obtenção de alumínio a partir \\
do minério e da reciclagem. & \\
& Propriedades: aspectos macroscópicos inalterados, manutenção do pH \\
Equilíbrios ácido-base no & Constituição: modelos para o estado de equilíbrio químico enfatizando seu caráter dinâmico; \\
corpo humano & a coexistência de reagentes e produtos no mesmo recipiente \\
ou & Transformações: reações químicas reversíveis \\
Ácidos e bases na saúde humana & Nomenclatura e Tabela Periódica: localização dos principais elementos constituintes das \\
ou & substâncias envolvidas nos processos estudados. Explicitação dos nomes das substâncias e \\
Reidratação e recomposição & suas fórmulas. \\
iônica do organismo & Aspectos Quantitativos: cálculo e discussão do significado das constantes de equilíbrio \\
&
\end{tabular}

Sugestão para a composição de um currículo com eixo conceitual Segundo Ano

Conceitos Químicos
Soluções: constituição, modelos; a natureza das espéci
em solução; concentração
Termoquímica: calor e temperatura; Introdução aos
fenômenos energéticos relevantes para a química;
calor de combustão; lei de Hess

Oxidação e redução: movimento de elétrons. Introdução aos fenômenos de oxidação e redução.

Oxidação e redução: movimento de elétrons. Introdução aos fenômenos de oxidação e redução.

Pilhas e células eletroquímicas

Gases: relações entre pressão, volume e temperatura para sistemas gasosos; a teoria cinético-molecular e o comportamento dos gases; reações químicas envolvendo gases em sistemas abertos e fechados

Equilíbrio Químico

Ácidos e bases
Principais contextos relacionados

Soluções no supermercado; Soluções na farmácia

Combustíveis fósseis; produção de energia a partir de alimentos; Produção de metais a partir de minérios; A água e a circulação de energia no planeta; Fontes alternativas de energia; Energia nuclear

Antissépticos, branqueamento, remoção de manchas; Radicais livres e o envelhecimento;

Galvanoplastia; Obtenção de alumínio

O oxigênio e o hidrogênio; Fotossíntese e respiração

\section{CONSIDERAÇÕES FINAIS}

É importante, para finalizarmos, apontar para as limitações, não só desta proposta mas de toda tentativa de reformulação curricular, considerando a realidade da Educação Brasileira. No segundo dos 3 encontros previstos no programa, como foi dito na introdução desse artigo, procurávamos saber dos professores se haviam aplicado alguns dos módulos, sejam os exemplares ou aqueles produzidos por eles, com o objetivo de avaliar as dificuldades enfrentadas na implementação da proposta curricular em sala de aula. Essas avaliações puderam explicitar a grande dificuldade que os Professores de Química de Minas
Equilíbrios ácido-base no corpo humano; Ácidos e bases na saúde humana; Reidratação e recomposição iônica do organismo
Gerais enfrentaram e continuam enfrentando para implementar qualquer mudança em sua prática pedagógica. Essas dificuldades passam pela falta de apoio institucional, pela ausência de um projeto pedagógico da escola, pela negativa das diretoras em aceitar turmas menores em que os alunos possam participar ativamente do processo de ensino-aprendizagem, pela falta de condições de trabalho, etc. Isso sem falar na situação salarial dos professores, que os obriga a manter uma carga horária muito elevada para compor um salário minimamente digno. Apesar de tudo isso, muitos foram os professores que tentaram e se mostraram realizados com a possibilidade de mudarem suas práticas pedagógicas e terem uma resposta positiva por 
parte dos alunos, satisfeitos com uma metodologia na qual têm participação mais ativa.

Esse processo de reformulação curricular não ocorreu sem as tensões e contradições que caracterizam as relações na escola e no sistema educacional. É contraditório, por exemplo, que o governo mineiro tivesse invistido nesses projetos e se recusasse a negociar um melhor salário para seus professores. Esse mesmo governo investia também pesadas somas em propaganda de seus projetos educativos, o que gerava alguma desconfiança sobre os reais objetivos desses projetos. Ao mesmo tempo, não podemos negar que tais iniciativas têm resultado em modificações nas práticas pedagógicas de muitos professores, abrindo novos horizontes de realização profissional. A produção de vários módulos pelos professores, alguns deles escolhidos para a publicação pela Secretaria de Educação é um exemplo concreto dessa abertura de novos horizonte. Mas é necessária uma avaliação mais profunda do real impacto de tais projetos no cotidiano da sala de aula.

\section{AGRADECIMENTOS}

Este trabalho foi realizado com suporte financeiro do $\mathrm{CNPq}$, Fundo Fundep/UFMG e Secretaria do Estado da Educação de Minas Gerais.

\section{REFERÊNCIAS E NOTAS}

1. Minas Gerais. Secretaria de Estado da Educação de Minas Gerais; 1998.

2. Lopes, A. R. C.; Química Nova na Escola 1995, 2.

3. Para a discussão sobre a questões de rituais e princípios no ensino ver: Edwards, D.; Mercer, N.; Common Knowledge - The development of undestanding in the classroom; Routledge; London, 1987. Mortimer, E. F., Mol, G. S., Duarte, L. P. Quím. Nova, 1994, 17, 243.

4. Ver, por exemplo, Lave, J.; Cognition in practice. Cambridge University Press; Cambridge, 1988.

5. Mortimer, E. F.; Quím. Nova 1997, 20, 200. Lakoff, G. Women, Fire and Dangerous Things: What categories reveal about the mind. University of Chicago Press, Chicago, 1987.

6. Mortimer, E. F.; Quím. Nova 1997, 20, 200.

7. Para a discussão de que os processos de interpretação de evidências experimentais são ativos e dependem dos conhecimentos prévios dos alunos possuem, ver, por exemplo: Driver, R., Asoko, H., Leach, J., Mortimer, E., Scott, P. Educational Researcher, 1994, 23, 5. Mortimer, E. F. e Machado, A. H. Anais do Encontro Linguagem Cultura e Cognição: Reflexões para o Ensino de Ciências. Belo Horizonte, UFMG, 1997, 139. 